\title{
Review: Selecting for improved feed efficiency and reduced methane emissions in dairy cattle
}

\author{
P. Løvendahl ${ }^{1 \dagger}$, G. F. Difford ${ }^{1,2}$, B. Li ${ }^{1,3}$, M. G. G. Chagunda ${ }^{4}$, P. Huhtanen ${ }^{5}$, M. H. Lidauer ${ }^{6}$, \\ J. Lassen ${ }^{1,7}$ and P. Lund ${ }^{8}$ \\ ${ }^{1}$ Department of Molecular Biology and Genetics, Aarhus University, DK 8830 Tjele, Denmark; ${ }^{2}$ Wageningen University and Research, NL 6708 Wageningen, The \\ Netherlands; ${ }^{3}$ Swedish University of Agricultural Sciences, SE 75007 Uppsala, Sweden; ${ }^{4}$ University of Hohenheim, DE 70599 Stuttgart, Germany; ${ }^{5}$ Swedish University \\ of Agricultural Sciences, SE 90183 Umeå, Sweden; ${ }^{6}$ Natural Resources Institute Finland (Luke), SF 31600 Jokioinen, Finland; ${ }^{7}$ Viking Genetics, DK 8900 Randers, \\ Denmark; ${ }^{8}$ Department of Animal Science, Aarhus University, DK 8830 Tjele, Denmark
}

(Received 31 January 2018; Accepted 27 August 2018; First published online 26 September 2018)

It may be possible for dairy farms to improve profitability and reduce environmental impacts by selecting for higher feed efficiency and lower methane $\left(\mathrm{CH}_{4}\right)$ emission traits. It remains to be clarified how $\mathrm{CH}_{4}$ emission and feed efficiency traits are related to each other, which will require direct and accurate measurements of both of these traits in large numbers of animals under the conditions in which they are expected to perform. The ranking of animals for feed efficiency and $\mathrm{CH}_{4}$ emission traits can differ depending upon the type and duration of measurement used, the trait definitions and calculations used, the period in lactation examined and the production system, as well as interactions among these factors. Because the correlation values obtained between feed efficiency and $\mathrm{CH}_{4}$ emission data are likely to be biased when either or both are expressed as ratios, therefore researchers would be well advised to maintain weighted components of the ratios in the selection index. Nutrition studies indicate that selecting low emitting animals may result in reduced efficiency of cell wall digestion, that is NDF, a key ruminant characteristic in human food production. Moreover, many interacting biological factors that are not measured directly, including digestion rate, passage rate, the rumen microbiome and rumen fermentation, may influence feed efficiency and $\mathrm{CH}_{4}$ emission. Elucidating these mechanisms may improve dairy farmers ability to select for feed efficiency and reduced $\mathrm{CH}_{4}$ emission.

Keywords: genetics, digestibility, microbiome, ranking, holobiont

\section{Implications}

An increasing number of studies show that feed conversion efficiency(FCE) is a heritable trait of dairy cows. In addition, daily methane $\left(\mathrm{CH}_{4}\right)$ emission has been shown in recent studies to be a heritable trait. Both traits are, to some degree, thought to be influenced by the composition of the rumen microbiome. There are indications of a favourable correlation between $\mathrm{CH}_{4}$ emission per $\mathrm{kg}$ of milk produced and $\mathrm{FCE}$, whereby more efficient cows may be emitting less $\mathrm{CH}_{4}$ per $\mathrm{kg}$ milk, which would facilitate the uptake of results by the dairy industry. However, the cost of systematic recording of feed intake and $\mathrm{CH}_{4}$ emission has hampered data analysis for large cohorts.

\section{Introduction}

\section{Target for research}

Researchers across multiple disciplines, including nutrition, genetics, breeding and microbiology, have turned their

\footnotetext{
${ }^{\dagger}$ E-mail: Peter.Lovendahl@mbg.au.dk
}

efforts towards understanding and improving dairy cow feed utilisation efficiency. Examples of cross-disciplinary projects tackling these goals include the Nordic 'Feed Utilization in Nordic Cattle' (http://projects.au.dk/func/), Ruminomics (http://www.ruminomics.eu/) and GplusE (http://www. gpluse.eu/) projects. Moreover, international collaborations have been formed to improve the statistical power of genetic studies through large cohorts, such as in the global Dry Matter Initiative (Berry et al., 2014).

Several collaborative $\mathrm{CH}_{4}$ mitigation and microbiome projects that are aligned with feed utilisation projects are based on the sharing of resources, such as rumen fluid samples (e.g. Ruminomics and EU-COST METHAGENE; http:// www.methagene.eu/). It is hoped that these efforts will form a scientific basis for improving feed efficiency and facilitating the implementation of improvements. Prior increases in milk production per dairy cow have diluted maintenance energy requirements per unit of produced milk, thereby reducing $\mathrm{CH}_{4}$ emissions per unit of milk (e.g. Capper et al., 2009; Gerber et al., 2013). However, further progress may be 
possible through the implementation of various new developments. The purpose of this review is to provide an overview, status update and insights into recent developments in dairy cow feed efficiency research, its connection with $\mathrm{CH}_{4}$ emissions and underlying mechanisms, such as digestibility and rumen microbiome functions. Each of these issues and their interactions are addressed in the review.

\section{Calculation and expression of efficiency}

The methodology for calculating and expressing feed efficiency determines the data required and, eventually, how selection based on a given efficiency variable will influence correlated traits. Commonly, efficiency is expressed as a ratio between product (outcome) and feed intake (expenses) in the form of mass or energy value of milk per kilogram of dry matter intake (DMI). A variable known as residual feed intake (RFI) has been applied successfully in chicken, pigs and beef cattle. Recently, there has been an interest in applying RFI measurements in lactating dairy cattle. Residual feed intake is calculated as the difference between measured and expected feed intake. Consequently, RFI values are centred around zero, with negative values indicating better efficiency. A somewhat similar variable called residual milk yield (RMY) has been proposed. For RMY, milk yield is the $y$-variate in the model and feed intake is a co-variate. In this paper, we provide examples and comparisons between alternative estimates of efficiency.

\section{Greenhouse gases and energy partitioning}

The greenhouse gas, $\mathrm{CH}_{4}$, is often assumed to represent a loss of energy, and thereby a drag on efficiency. If so, $\mathrm{CH}_{4}$ measurements could be useful as an indicator of energy loss and, by extension, efficiency. However, animal data on this at large scale have not been available or reported, but could have potential as indicator traits. A thorough review of $\mathrm{CH}_{4}$ measurement methodologies has been provided by Hammond et al. (2016a), supplemented by the works of Bell et al. (2014) and Negussie et al. (2017). New methods with the capacity to test groups of cows have provided estimates of genetic variation in $\mathrm{CH}_{4}$ emission from Holstein cows (Lassen and Løvendahl, 2016). As new methods are validated and improved (e.g. Difford et al., 2016a), their statuses and associated advances need to be updated continually, but a comprehensive methodology update is beyond the scope of this review.

Beyond their importance with respect to climate change, $\mathrm{CH}_{4}$ emissions are also a conduit of energy loss. Eructed $\mathrm{CH}_{4}$ has been estimated to account for $2 \% \sim 12 \%$ of ingested feed energy (Johnson and Johnson, 1995). Thus, it may be possible to use direct or indirect selective breeding strategies to reduce such energy losses and thus potentially improve feed efficiency. Such an endeavour will require ample volumes of data tracking feed efficiency subtraits along with good emission data from large cohorts of cows. The case for dairy cows is especially complex owing to tissue mobilisation factors interacting with daily intake and production traits. Consequently, we need to address efficiency beyond short periods of time, perhaps for whole life-cycles, with intensive recordkeeping throughout. Meanwhile, other traits affected by energy status, such as fertility and disease resistance (treated only briefly here) should be tracked concomitantly.

\section{Feed efficiency and digestion}

Feed efficiency depends upon an animal's ability to transform ingested feed into metabolically available nutrients. It was long assumed that digestibility was similar across individuals. However, it has become evident that individual cows differ in their ability to digest various feedstuffs (Huhtanen et al., 2015; Cabezas-Garcia et al., 2017). These differences in digestibility among dairy cows are worthy of further study given that even small improvements can, on a large scale, provide substantial value.

Dairy cows host huge microbiomes in their digestive tracts that enable them to digest feed with a high-fibre content while releasing $\mathrm{CH}_{4}$ as a by-product. Recent advancements in DNA sequencing technologies have made it possible to examine microbiome organisms as well as host-microbiome interactions. The application of such technology platforms to rumen fluid microbiomes from many cows may provide further insights into both digestion and $\mathrm{CH}_{4}$ production. This review is intended to provide insights into aspects of feed efficiency, $\mathrm{CH}_{4}$ emission and rumen-microbiome interactions with a focus on the variation and co-variation of traits across individual cows.

\section{Defining and estimating feed efficiency variation}

\section{Definition of feed efficiency}

A simple, oft-used definition of feed efficiency is based on FCE, a trait-based ratio calculated as energy-corrected milk (ECM) per kilogram DMI (Hurley et al., 2016). The RFI definition - in its simplest form, the difference between actual intake and expected intake based on diet composition, BW change and milk energy production - is gaining favour. Unless live weight changes $(\Delta \mathrm{LW})$ are accounted for, this simple definition of RFI resembles that of energy balance, which may have confounding responses to fertility and health. Residual milk yield (the converse of RFI) has also been described as an efficiency trait (Hurley et al., 2016). Each of these definitions has advantages and disadvantages. Because of time-related fluctuations in variables, such as BW, the error associated with any of them can be reduced by extending recording periods. In the following section, we will address these issues in more detail based on findings in the literature and a phenotypic example from Jersey cow data.

\section{Residual feed intake}

Efficiency trait estimation depends upon the recording of feed intake and some traits accounting for energy sinks. Commonly, RFI calculations are done by a two-step procedure (e.g. Berry and Crowley, 2013), where the first step is a linear regression of DMI encompassing the factors of metabolic BW (MBW), ECM and $\Delta \mathrm{LW}$ to account for body tissue 
mobilisation (equation (1)). Other definitions have also included body condition score (BCS) changes, as well as combinations of $\triangle \mathrm{LW}$ and $\mathrm{BCS}$.

$$
\mathrm{DMI}=\mu+\beta_{1} \mathrm{MBW}+\beta_{2} \mathrm{ECM}+\beta_{3} \Delta \mathrm{LW}+\mathrm{RFI}
$$

The partial regressions in equation (1) are $\beta_{1}, \beta_{2}$ and $\beta_{3}$, making RFI a residual from the regression model. In the second step (equation (2)), RFI is modelled against relevant fixed effects, such as feeding regime, herd, season and parity. The random part of the model includes animal effects at two levels if cows are recorded repeatedly, where genetic relationships $\left(\mathrm{COW}_{\mathrm{A}}\right)$ form one level and 'permanent animal effects' $\left(\mathrm{COW}_{\mathrm{PE}}\right)$ form another.

$$
\mathrm{RFI}=\sum \text { Fixed effects }+C O W_{P E}+C O W_{A}+\varepsilon
$$

As a residual of equation (1), RFI has a mean of zero. The random genetic effect of cows $\left(\mathrm{COW}_{\mathrm{A}}\right)$ and the permanent animal effect $\left(\mathrm{COW}_{\mathrm{PE}}\right)$, which includes learnt and nongenetic effects that persist in the life of the animal, come out as random solutions from equation (2). If this model is used at the phenotypic level only, the $\mathrm{COW}_{\mathrm{A}}$ plus $\mathrm{COW}_{\mathrm{PE}}$ effects are joined in a single COW effect. The two steps can be joined into a unified model, as shown in equation (3).

$$
\begin{aligned}
\mathrm{DMI}= & \mu+\beta_{1} \mathrm{MBW}+\beta_{2} \mathrm{ECM}+\beta_{3} \Delta \mathrm{LW} \\
& +\sum \text { Fixed effects }+\operatorname{COW}_{P E}+\mathrm{COW}_{A}+\varepsilon
\end{aligned}
$$

In equation (3), all effects are estimated simultaneously, reducing effect biases and residual variances (Tempelman et al., 2015). If researchers employ serial (e.g. weekly) data recorded over a period of lactation (Berry et al., 2014; Li et al., 2017), the linear regression coefficients in equation (1) change systematically with lactation stage, which impacts the estimated variance components, resulting, generally, in larger errors (Li et al., 2017). Factors that change with lactation stage include, in addition to co-varying fixed regressions, a set of variance components, namely the genetic $\left(\mathrm{COW}_{\mathrm{A}}\right)$, permanent animal $\left(\mathrm{COW}_{\mathrm{PE}}\right)$ and residual components (Liinamo et al., 2015; Tempelman et al., 2015; Hurley et al., 2016; Li et al., 2017). Some studies have included records from multiple parities, assuming a repeatability model to be adequate (e.g. Hurley et al., 2016), whereas others have focussed on primiparous cows (e.g. Li et al., 2017). Although Holstein cows are common in Europe and used for most RFI studies, other breeds are also in commercial use, including Red Dairy cattle and Jersey cows. However, there are few reports on feed efficiency in these breeds (e.g. Liinamo et al., 2015).

\section{Residual milk yield}

The RFI approach focusses on production cost, dividing it over a range of sinks, including milk production. Shifting focus from cost to income, DMI and ECM can exchange positions in the RFI model to obtain an estimated RMY (equation (4)) (Hurley et al., 2016):

$$
\mathrm{ECM}=\mu+\gamma_{1} \mathrm{MBW}+\gamma_{2} \mathrm{DMI}+\gamma_{3} \Delta \mathrm{LW}+\mathrm{RMY}
$$

This RMY model can be extended in a manner similar to that used with the RFI model to include cow effects and fixed effects in one unified model.

$$
\begin{aligned}
\mathrm{ECM}= & \mu+\gamma_{1} \mathrm{MBW}+\gamma_{2} \mathrm{DMI}+\gamma_{3} \Delta \mathrm{LW} \\
& +\sum \text { Fixed effects }+\operatorname{COW}_{P E}+\operatorname{COW}_{A}+\varepsilon
\end{aligned}
$$

Note that, in (equation (5)), the partial regressions changed from $\beta$ in the RFI model to $\gamma$ in the RMY model, whereas the other terms remain similar. Consequently, efficient cows with negative RFI values would have positive RMY values. The interpretation of RMY becomes the deviation in milk yield at a constant feed intake, adjusted for MBW and $\Delta \mathrm{LW}$. Owing to the favourability of positive values, RMY is easier to comprehend than RFI.

\section{Challenges associated with using residual feed intake and residual milk yield}

The method of recording feed intake and feeding level may affect RFI and RMY results. Hurley et al. (2016) used data from pasture-maintained Holstein cows and recorded intake by way of the indirect $n$-alkane method. Although this method is well documented, the grazing situation differs from that of housed total mixed ration-fed cows. International consortium findings indicate that environmental differences may be so substantial that genetic correlations with DMI deviate strongly from unity (Berry et al., 2014). The timeframe for estimation is also important. Recording windows may be shortened (to days or weeks) to enable more animals to be tested within a given facility each year. Thus, there is a need to select a timeframe likely to reflect the whole lactation-period or life-span efficiency, such as the more stable mid-lactation period (Hooven et al., 1972; VandeHaar et al., 2016; Hardie et al., 2017).

\section{Comparison of efficiency measures based on a study with Jersey cows}

We have used recent data from Jersey cows kept at the Danish Cattle Research Centre (Foulum, Denmark) to compare efficiency measures. The calculations began with raw data, using weekly averages of traits (Li et al., 2017), DMI, $\mathrm{ECM}, \mathrm{LW}$ and $\mathrm{MBW}=\mathrm{LW}^{0.75}$. Daily $\Delta \mathrm{LW}$ was considered more useful than LW and therefore calculated with smoothed data. Data recording began just after calving ( 5 days in milk (DIM)) and continued throughout lactation until drying off, or culling or 305 DIM. Cows in parity 1 and 2 with at least 32 weeks of data in the first 40 weeks post-parturition were included. All cows were fed ad libitum with partial mixed rations plus $3 \mathrm{~kg}$ of concentrates per day during milking with an automated milking system (see Li et al., 2017 for recording procedures). Additional analyses included variables as lactation means: average DMI (AVG_DMI), average ECM (AVG_ECM) and average FCE (AVG_FCE), based on ECM/DMI ratios. 
The specific models used were of the unified type, including an RFI model (6) and an RMY model (7), with each parity modelled separately.

$$
\begin{aligned}
& \mathrm{DMl}_{j k l}=\mu+Y_{m}+S_{j}+\beta_{1} \mathrm{MBW}+\beta_{2} \operatorname{ECM}\left(S_{j}\right)+\beta_{3} \Delta \mathrm{LW}\left(S_{j}\right) \\
& +W_{l}+\operatorname{COW}_{k j}+\sum_{n=1}^{3}\left(\begin{array}{c}
\tau_{1 n} \cos (n \varphi) \\
+\tau_{2 n} \sin (n \varphi)
\end{array}\right)+\varepsilon
\end{aligned}
$$

$$
\begin{aligned}
& \mathrm{ECM}_{j k l}=\mu+Y_{m}+S_{j}+\gamma_{1} \mathrm{MBW}+\gamma_{2} \operatorname{DMI}\left(S_{j}\right)+\gamma_{3} \Delta \mathrm{LW}\left(S_{j}\right) \\
& +W_{l}+\operatorname{COW}_{k j}+\sum_{n=1}^{3}\left(\begin{array}{l}
\omega_{1 n} \cos (n \varphi)+ \\
\omega_{2 n} \sin (n \varphi)
\end{array}\right)+\varepsilon
\end{aligned}
$$

The effects are as in models (4) and (5), with added factors for recording year $\left(Y_{m}\right)$, seasons modelled as order-3 Fourier terms, where $\varphi$ is the day of the year measured in radians, $\tau$ and $\omega$ are regression coefficients. Lactation curves were modelled by week of lactation $\left(W_{1}\right)$. Random cow effects (COW) were also nested within the segments to allow variance components to change during lactation. Random solutions for each cow within the segment were extracted and used to estimate correlations between and within traits. Estimates of fixed and random effects were obtained by the MIXED procedure in SAS software (SAS Institute Inc., Cary, North Carolina, USA).

An overview of the raw data is given in Table 1, with 269 first and 189second parity cow-lactations contributing to the data. Cows in second parity had a higher feed intake and larger yield, but gained less weight during the lactation period than first lactation cows.

The partial regressions of DMI on ECM and $\Delta \mathrm{LW}$ reflect the amount of DMI per kilogram ECM or per kilogram $\Delta \mathrm{LW}$, respectively. The coefficients changed over the trajectory of lactation in similar ways in first and second parity cows (Figure 1a and b). Similar partial regression changes were described by Li et al. (2017) in first parity Holstein cows. The changes in regression coefficients were gradual over the lactation period for regression of DMI on ECM (Figure 1b). The regressions of DMI on $\Delta \mathrm{LW}$ showed a peak in early lactation and another peak 6 to 8 months into lactation (Figure 1b). There is no obvious, simple reason for these unexpected peaks, which need to be studied further, especially given that they were seen in both in first and second parity cows. Regressions on MBW (and thereby also on LW) were constant over the lactation period $(0.0974 \pm 0.0055 \mathrm{~kg}$ $\mathrm{DMI} / \mathrm{MBW} \times$ day) and therefore not shown in figures. Changes in regression coefficients over the lactation period may reflect interactions with mobilisation of body energy (body composition) that were ignored in the models, or may reflect digestibility changes that were also not accounted for in the models.

Partial regressions of ECM on DMI and $\triangle \mathrm{LW}$ during lactation (Figure 2a and b) differed clearly from those of the DMI regressions presented in Figure 1. The regression coefficients cannot be compared directly because they have different units, and the pattern of development over lactation differs for the covariates DMI and $\Delta \mathrm{LW}$. Although they are supposed to be mirror images, they are not exactly so, possibly due to correlations between these covariates. The regression of ECM on MBW was small and not significant.

Trait consistency over weeks in lactation was examined vis-à-vis correlations between random cow solutions from each of 10 4-week segments in first parity cows (Figure 3), and for each segment with an overall estimate per lactation (AVG). For RFI, adjacent segments correlated strongly, whereas distant segment correlations approached zero, especially between early and late lactation stages (Figure 3). However, from the fourth 4-week lactation segment onwards, correlation coefficients surpassed 0.40 , and correlations with average lactation were high by the third segment.

Rank correlations between RMY solutions at different lactation stages were, in general, somewhat higher than those for RFI, albeit with similar reductions for correlations between distant segments (Figure 3). A similar pattern of results with very similar values was obtained for second parity cows (data not shown). These results indicated that treating RFI and RMY as trait characteristics based only on a single 4-week segment for each cow does not yield results that are highly consistent across short-term lactation periods, though the results correlate well with complete lactation values. These findings support previous findings in Holstein cows (Li et al., 2017), indicating that if RFI or RMY is evaluated in only part of the lactation period, it is best done in the more stable part of lactation (months $3 \sim 6$ ) when segments correspond most closely with the entire lactation period. However, limiting subjects to the stable lactation

Table 1 Feed efficiency data from first- and second-parity Jersey cows

\begin{tabular}{lcccc}
\hline \hline & \multicolumn{2}{c}{ Parity 1 (269 cows, 10 440 records) } & & Parity 2 (189 cows, 7322 records) \\
\cline { 2 - 3 } Parameters & Mean (SD) & Range & Mean (SD) & Range \\
\hline DMI (kg/day) & $16.1(2.8)$ & 5.6 to 34.5 & $19.0(3.2)$ & 5.95 to 39.7 \\
ECM (kg/day) & $25.8(5.0)$ & 2.8 to 48.6 & $30.8(6.3)$ & 5.21 to 51.2 \\
LW (kg) & $441.0(45.0)$ & 254 to 631 & $485.0(46.0)$ & 260 to 694 \\
$\Delta$ LW (kg/day) & $0.191(0.512)$ & -12.2 to 4.2 & $0.150(0.483)$ & -6.3 to 5.4 \\
MBW (kg.75) & $96.1(7.4)$ & 63.5 to 125.9 & $103.2(7.4)$ & 64.7 to 135.3 \\
FCE & $1.62(0.35)$ & 0.23 to 5.98 & $1.63(0.34)$ & 0.45 to 6.04 \\
\hline \hline
\end{tabular}

$\mathrm{DMI}=$ dry matter intake; $\mathrm{ECM}=$ energy corrected milk yield; $\mathrm{LW}=$ live weight; $\Delta \mathrm{LW}=$ daily change in live weight; $\mathrm{MBW}=$ metabolic $\mathrm{BW} ; \mathrm{FCE}=$ feed conversion efficiency . Data in the table reflect weekly records of DMI, ECM, LW, $\triangle \mathrm{LW}, \mathrm{MBW}$ and FCE (FCE = ECM/DMI). 
(a)

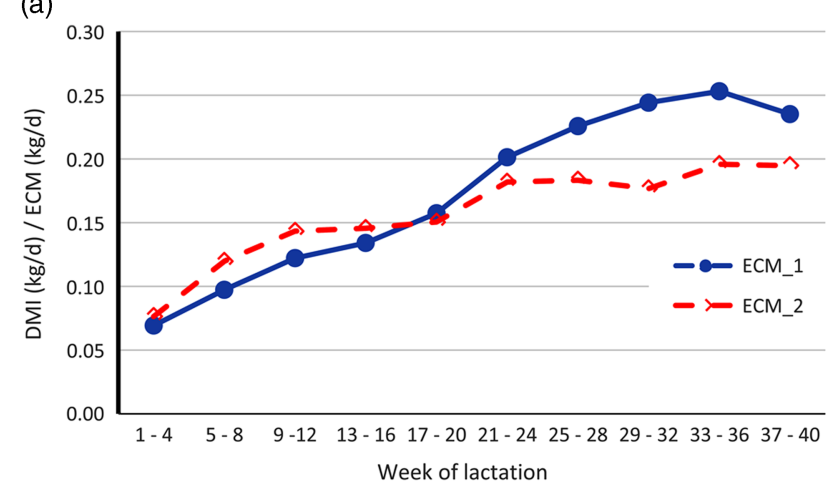

(b)

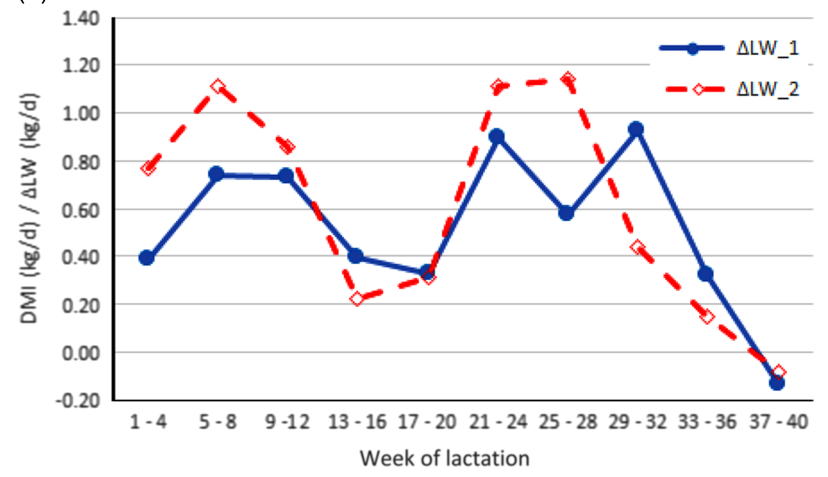

Figure 1 Estimated regression coefficients for dry matter intake (DMI) $v$. energy-corrected milk (ECM) (a) and DMI $v$. live weight changes $(\Delta L W)$ (b) across ten 4-week lactation periods in first-parity $(1)$ and secondparity (2) Jersey cows.

phase may reduce contemporary group sizes due to cows being in different stages of lactation at the time of recording.

Although RFI and RMY are both used as indices of efficiency, there are divergences in the animal rankings they yield (Figure 3). All rank correlations were in the range of -0.25 to 0.25 , with positive and negative correlation values being observed mainly in early and late lactation phases, respectively. Theoretically, we would expect negative correlations between RFI and RMY values. However, in second parity cows, we tended to see RFI-RMY correlation values close to zero (data not shown). These findings contrast with prior results seen in grazing Holstein cows (Hurley et al., 2016). Notwithstanding, the lack of a strong correlation indicates that the two measures are distinct indicators of efficiency.

Summary data covering entire lactation periods may be more relevant than data limited to particular phases within the lactation period. Therefore, additional analyses were carried out with models (6) and (7), where the cow effect was assumed to be constant across the entire lactation period, and the results were aligned with the simple means of DMI, ECM and FCE (Table 2).

As expected, milk yield and feed intake correlated strongly in both first and second parity cows, such that higher yield and higher feed intake followed each other. The FCE ratio (ECM/DMI) correlated robustly with milk yield but not DMI, reflecting the fact that more efficient cows had higher milk
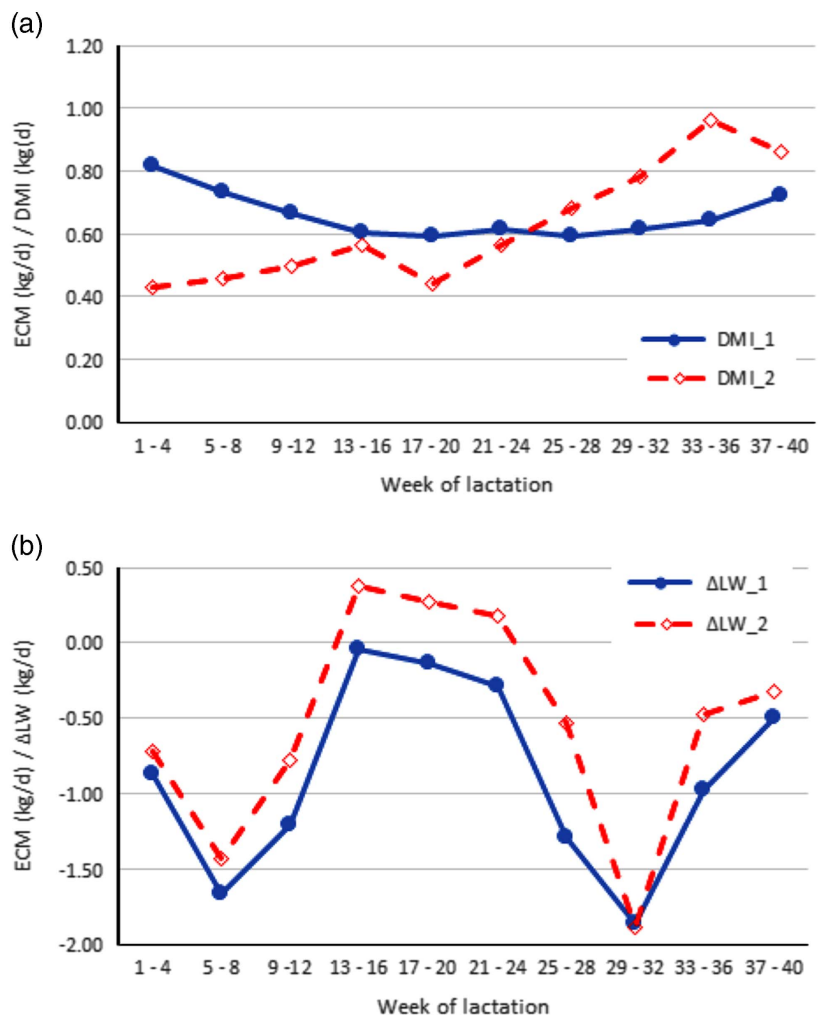

Figure 2 Estimated regression coefficients for energy-corrected milk (ECM) v. dry matter intake (DMI) (a) and ECM v. live weight changes $(\Delta \mathrm{LW})(\mathrm{b})$ ratios across ten 4 -week lactation periods in first-parity ( 1 ) and second-parity (_2) Jersey cows.

yields, but not higher feed intake. Residual feed intake correlated positively with feed intake, but not with milk yield, MBW or $\Delta \mathrm{LW}$, suggesting that efficient (i.e. low RFI) cows eat less. In contrast, efficient RMY cows have higher milk yields and, by definition, at similar feed intake levels, higher MBW and $\Delta L W$ values, suggesting that efficient RMY cows (i.e. cows with a high RMY) produce more milk. Residual feed intake and RMY tended to correlate negatively with each other, as found by Hurley et al. (2016), demonstrating that the choice of efficiency index can have a pronounced impact on data interpretation and the ranking of animals. It is noteworthy that ECM/DMI ratio data, a traditional measure of $F C E$, correlated substantially better with RMY data than with RFI data. Furthermore, FCEassociated traits, with the exception of $\Delta \mathrm{LW}$, were found to have moderate to high repeatability, across first and second parity cows.

The strengths of our estimated RFI-DMI correlations were similar to or higher than those reported previously for lactating Holstein cows (Connor, 2015; Hurley et al., 2016). Our RMY-ECM correlations were strong in both first and second parity cows (Table 2), largely in agreement with the findings of Hurley et al. (2016). Furthermore, we found that RMY correlated positively with FCE, extending the findings of Hurley et al. (2016) to Jersey cows housed indoors and sustained on total mixed ration feed. 

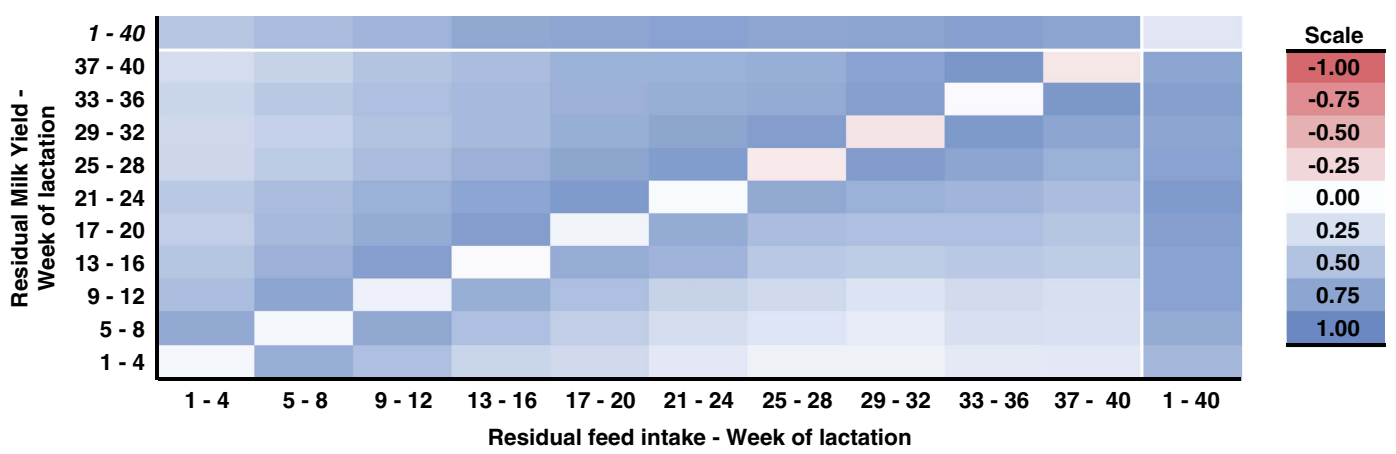

Figure 3 Rank correlations between random animal solutions for residual feed intake (below diagonal) and residual milk yield (above diagonal) for ten 4 weeks of lactation segments in first-parity Jersey cows. Correlations between RFI and RMY in the same segment are in the diagonal. Correlations to complete lactation solutions are indicated as ' $1-40$ '. Colour intensity reflects correlation strength. Correlations above 0.12 or below -0.12 were significant $(P<0.05)$.

Table 2 Correlations among cow random solution parameters in firstand second-parity (italics) Jersey cows

\begin{tabular}{lrrrrrrr}
\hline \hline Parameters & DMI & ECM & FCE & $\Delta$ LW & MBW & RFI & RMY \\
\hline DMI & 0.67 & 0.58 & -0.03 & -0.14 & 0.18 & 0.80 & 0.0 \\
ECM & 0.64 & $\mathbf{0 . 6 7}$ & 0.79 & -0.23 & 0.16 & 0.0 & 0.79 \\
FCE & -0.11 & 0.68 & 0.47 & -0.18 & 0.03 & -0.59 & 0.97 \\
$\Delta$ LW & -0.15 & -0.18 & -0.10 & 0.03 & 0.10 & 0.0 & 0.0 \\
MBW & 0.25 & 0.24 & 0.03 & 0.10 & 0.84 & 0.0 & 0.0 \\
RFI & 0.76 & 0.0 & -0.70 & 0.0 & 0.0 & 0.47 & -0.56 \\
RMY & 0.0 & 0.76 & 0.97 & 0.0 & 0.0 & -0.61 & $\mathbf{0 . 5 7}$ \\
\hline \hline
\end{tabular}

$\mathrm{DMI}=$ dry matter intake; $\mathrm{ECM}=$ energy-corrected milk; $\mathrm{FCE}=$ feed conversion efficiency; $\Delta \mathrm{LW}=$ live weight change; $\mathrm{MBW}=$ metabolic $\mathrm{BW}$; $\mathrm{RFI}=$ residual feed intake; RMY = residual milk yield.

Analysed parameters include RFI, RMY and lactation means for DMI, ECM, FCE $(\mathrm{FCE}=\mathrm{ECM} / \mathrm{DMI}), \Delta \mathrm{LW}$ and $\mathrm{MBW}$.

In the diagonal are correlations between first and second parity for the same trait (bold).

Correlations with absolute value above 0.13 were significant.

It is tempting to suggest that efficiency can be seen in two dimensions, namely an input and an output. If RMY is used for selection, cows with a higher yield at a fixed feed intake will be found to be the more efficient ones. If RFI is used, cows who eat less while producing a given fixed yield will be found to be the more efficient ones. In any case, the key to identifying the most efficient cows is to have comprehensive records of both milk yield and feed intake for large groups of cows, preferably over most or all lactation stages.

The presently observed close correlation between RFI and energy balance, representative of efficient cows having a more negative energy balance, might impact fertility trait selection negatively. This aspect needs to be investigated further using empirical data before solid recommendations can be made as to the implementation of an efficiency traitbased breeding programme.

\section{Measuring emissions from animals en masse}

The preferable method of $\mathrm{CH}_{4}$ emission assessment depends upon the purpose of the assessment. Target emission levels differ across countries, farm inventories and individual animals' current life stages. The relative importance of performance specifications, such as precision, accuracy and capacity, may depend on the application of measurements, which determines the statistical power of key parameter estimates.

There is an ongoing debate about methods and priorities. As new methods continue to be developed, there has been a growing emphasis on accuracy among nutrition-focussed scientists, whereas geneticists, who are relatively new to this field, have been more focussed on high capacity. Comparisons of the available methods have pointed to the importance of comparing and validating any new technique against an accepted gold standard, such as respiration chambers, to gauge relative differences in performance specifications (Hammond et al., 2016a; Cabezas-Garcia et al., 2017; Negussie et al., 2017; Hristov et al., 2018). Although it is a less attended-to issue in the literature, it is similarly important for genetic studies to compare animals, and estimate the differences between them, accurately under standardised conditions.

Although the performance specifications (i.e. precision, accuracy and capacity) of alternative techniques are being estimated through comparison with a gold standard, it is important to remain mindful of parameter inter-relatedness and joint influences on technique applicability across different target levels. All $\mathrm{CH}_{4}$ emission measures have some level of error. However, the type of error can differ. For instance, a systematic error or mean bias in accuracy refers to the circumstance where a method records emission data that differ from data obtained by the gold standard reference method by a consistent value. If the systematic error relative to the gold standard is known, then it can be corrected with a calibration equation or statistical modelling of a fixed effect (Barnhart et al., 2007). Errors of precision, including random errors or noise, refer to the presence of a higher residual/ background error rate than is seen with the gold standard. Correcting imprecision is far more challenging than correcting inaccuracy because doing so requires mechanical or technical changes (e.g. improving hardware), augmenting the method's capacity for processing repeated 
measurements, or improving statistical modelling of random effects on a per subject basis (Roy, 2009). Hence, a method that is less accurate than the gold standard, but precise, can be used in place of the gold standard method if the performance specifications relative to the gold standard are known and able to be adjusted appropriately.

Measures of $\mathrm{CH}_{4}$ emission traits include daily emission rate or daily flux (I or g/day animal), $\mathrm{CH}_{4}$-yield related to feed intake (e.g. $\mathrm{CH}_{4} \mathrm{~g} / \mathrm{kg} \mathrm{DMI}$ ) and $\mathrm{CH}_{4}$-intensity related to production (g or l/kg ECM) (Negussie et al., 2017). Daily $\mathrm{CH}_{4}$ emission rate measurement has the advantage of sharing features with milk yield per day, whereas the two latter parameters are simple ratios between emission rate and feed intake or milk yield. Although basic measurements obtained from most techniques are converted to an emission rate, an emission rate is sometimes estimated by multiplying a basic measure by an estimate of energy intake derived from milk yield (e.g. Madsen et al., 2010). In such cases, estimated fluxes are then converted to $\mathrm{CH}_{4}$-intensity in rather circular way, by dividing the emission rate by milk energy output. In such instances, it would preferable to continue with the basic measures (e.g. the $\mathrm{CH}_{4}: \mathrm{CO}_{2}$ ratio used by Madsen et al., 2010; Lassen et al., 2012 and Bell et al., 2014). Not only would it be easier, but it avoids the possibility of assumptions creating bias, and perhaps inaccuracy, in the conversions (Arndt et al., 1991; Raubenheimer, 1995). The critical requirements for geneticists are capacity and similarity in the ranking of animals across methods (Difford et al., 2016a).

There has been a great interest among geneticists in using milk fatty acid composition or milk IR spectra as an indicator of $\mathrm{CH}_{4}$ emissions (e.g. Dehareng et al., 2012). These approaches are attractive because they can be obtained for all cows within a milk recording programme and doing so is inexpensive because the data are already generated for milk component analysis. Although the predictive value of such data are very good when calibrated relative to experimental data (Vanlierde et al., 2015), the validity of the approach was only partly confirmed in larger studies of cows kept under conditions more similar to commercial herd conditions (Shetty et al., 2017). The potential for using mid-IR spectrometry data as an indicator of DMI or feed efficiency has initially shown some promise, though the findings of Shetty et al. (2016) raise concerns regarding whether that approach can be experimentally reliable.

\section{Rumen microbiome and rumen fermentation}

Between-animal variation in $\mathrm{CH}_{4}$ emissions can be attributed to a variety of factors, including individual differences in rumen microbiome, digestive functions and metabolic regulation, and the interactions between these factors. Rumen microbiome effects on $\mathrm{CH}_{4}$ emissions have been studied intensively, but the results remain inconclusive. Firkins and $\mathrm{Yu}$ (2006) concluded that the abundance of methanogens might not be a reliable indicator of ruminant $\mathrm{CH}_{4}$ emissions. Methanogen densities did not differ between rumen samples from high and low emitters, but archaeal community structure did differ across rumen samples associated with different $\mathrm{CH}_{4}$ yields (Kittelmann et al., 2014). Part of the inconsistency between $\mathrm{CH}_{4}$ emissions and archaea abundance could be related to differences in the expression of genes involved in the methanogenic pathway. Shi et al. (2014) found that although the abundance of methanogens and methanogenesis pathway genes were similar between low and high $\mathrm{CH}_{4}$ emitters, the transcription of these genes was substantially higher in high emitters.

If rumen microbiomes play a major role in explaining interanimal variations in $\mathrm{CH}_{4}$ emissions, then such differences should be reflected in rumen fermentation patterns because molar proportions of rumen volatile fatty acids (VFAs) reflect the balance between $\mathrm{H}_{2}$ production (acetate and butyrate) and $\mathrm{H}_{2}$ utilisation (propionate). In a recent meta-analysis of rumen fermentation data from dairy cow-digestion studies, Cabezas-Garcia et al. (2017) found a between-cow $\mathrm{CV}_{\text {in }} \mathrm{CH}_{4}$ yield per mole VFA (calculated according to Wolin, 1960) of only 0.01 , with low repeatability $(t=0.11)$. Such results suggest that rumen microbiome differences are not strongly related to the end-products of fermentation and thus $\mathrm{CH}_{4}$ emission. Pinares-Patiño et al. (2003) found a $\mathrm{CV}$ for $\mathrm{CH}_{4}$ yield of 0.098 in a study of 10 sheep with low variability in molar proportions of acetate, propionate and butyrate $(0.011,0.047$ and 0.036 , respectively). Small betweenanimal variation in rumen fermentation patterns relative to $\mathrm{CH}_{4}$ emission variation is inconsistent with the rumen microbiome being a major factor in determining betweenanimal differences in $\mathrm{CH}_{4}$ emission.

It is reasonable to expect that VFA concentrations may be related to animal factors such as rumen volume, passage rate and absorption rate, whereas VFA proportions are more likely to be influenced by the rumen microbiome than animal factors. Cabezas-Garcia et al. (2017) found that betweencow variability and repeatability of ruminal VFA concentrations was much greater than the corresponding parameters for molar proportions of VFA, suggesting that diet and animal factors have a greater impact on $\mathrm{CH}_{4}$ emissions than the rumen microbiome. Notwithstanding, it remains a concern that currently available microbiome characterisation methods are not adequate for determining what traits are predictive of $\mathrm{CH}_{4}$ emission.

\section{Animal factors}

Cabezas-Garcia et al. (2017) found that the between-cow variability and repeatability of the NDF pool $(\mathrm{g} / \mathrm{kg} B W)$ of rumen and the indigestible-NDF passage rate were much greater than the variability and repeatability of variables describing rumen fermentation patterns. Smuts et al. (1995) reported that rumen digesta retention time data were repeatable $(t=0.45)$. Levels of $\mathrm{CH}_{4}$ produced appear to be strongly inversely related to the rate of digesta passage from the rumen (Pinares-Patiño et al., 2003 and 2011; Goopy et al., 2014). Pinares-Patiño et al. (2003) obtained a particulate passage rate-to- $\mathrm{CH}_{4}$ yield correlation coefficient of -0.75 , a level of $\mathrm{CH}_{4}$-relatedness similar to that seen with feeding level. It is well known that increased feeding reduces digesta retention time and $\mathrm{CH}_{4}$ yield (Johnson and Johnson, 
1995). Analyses of Yan et al. (2000) and of Ramin and Huhtanen (2013) showed that $\mathrm{CH}_{4}$ yield decreases about $10 \%$ per multiple of maintenance increase in feeding level. Increasing feeding raises the digesta passage rate, which reduces diet digestibility and increases the efficiency of microbial cell synthesis partitioning of fermented carbon from gasses and VFA to microbial cells (Russell et al., 1992); microbial cells are more reduced than fermented carbohydrates (Czerkawski, 1986; Van Soest, 1994).

\section{Animals as hosts for the microbiome}

Modern ruminants and the diverse ecosystems of rumen microorganisms within them have been coevolving for some 50 million years. The rumen provides an anaerobic environment hospitable to microorganisms, which ferment and digest plant material into nutrients that are absorbed by the host. This commensal relationship has been highly successful in allowing ruminants and rumen microorganisms to thrive in harsh and widely distributed environments on high cellulose plant diets, which are indigestible to most other domains of life. This co-dependence is such that the ruminant host cannot survive without the microorganisms and some rumen microorganisms are not found outside of ruminants (e.g. rumen protozoa) or are highly differentiated from related microbes (e.g. methanogenic archaea) (Knapp et al., 2014).

The rumen microbial ecosystem, henceforth referred to as the rumen microbiome, contains many domains of life, most of which have not been cultured or annotated, but can be described by culture-independent molecular techniques, such as ribotyping, metagenomics or meta-transcriptomics (Denman and McSweeney, 2014). The relative microbial domain biomass percentages have been estimated as follows: protozoa, $40 \%$ to $50 \%$; bacteria, $26 \%$ to $42 \%$; fungi, $1 \%$ to $20 \%$; and archaea, $0.3 \%$ to $4.0 \%$ (Wallace et al., 2014; Tapio et al., 2017). From the limited annotations and cultured representatives described, it has been determined that plant structural carbohydrates are degraded to 5 - and 6 carbon sugars and then further converted into VFAs for host energy metabolism, with $\mathrm{CO}_{2}$ and $\mathrm{H}_{2}$ by-products being absorbed primarily by bacteria, protozoa and fungi (Moss et al., 2000). Fermentation efficiency is limited to a narrow range of $\mathrm{H}_{2}$ partial pressure and $\mathrm{pH}$, such that a drop in $\mathrm{pH}$ inhibits fermentation (McAllister and Newbold, 2008). Methanogenic archaea are thought to play an important role in modulating the partial pressure of $\mathrm{H}_{2}$ and regulating $\mathrm{pH}$ in the rumen by converting $\mathrm{H}_{2}$ and $\mathrm{CO}_{2}$ into $\mathrm{CH}_{4}$. This interspecific hydrogen transfer is seen as a link between $\mathrm{CH}_{4}$ production and the efficiency of fibre digestion.

\section{Digestibility}

Herd et al. (2004) suggested that diet digestibility may underlie, at least in part, RFI variation. Herd and Arthur's (2014) review paper also provided evidence showing that digestibility is negatively associated with RFI (low residual feed intake $=$ high efficiency), indicating that more efficient animals have greater diet digestibility. To have a major contribution to variation in feed efficiency, digestibility should vary between animals and be repeatable. Based on carefully conducted digestibility experiments, Van Soest (1994) concluded that between-animal variation is about $20 \mathrm{~g} / \mathrm{kg}$ with respect to starch digestibility. Part of this variation appears to be random when measurements are based on one replicate per animal. In a meta-analysis by CabezasGarcia et al. (2017), between-cow variation in starch digestibility was small (starch digestibility $=10 \mathrm{~g} / \mathrm{kg} ; \mathrm{CV}=$ 0.013 ). These data originated from changeover studies in which digestibility was determined mostly by the total faecal collection method. Mehtiö et al. (2016) reported a betweencow organic matter digestibility (OMD) variation of $12.3 \mathrm{~g} /$ $\mathrm{kg}$, determined using acid-insoluble ash as an internal marker. Huhtanen et al. (2016) obtained lower variability (SD = $8.8 \mathrm{~g} / \mathrm{kg} ; \mathrm{CV}=0.012$ ). Berry et al. (2007) reported a greater variability for grazing cows when digestibility was determined using alkanes as a marker, probably because they used only one replicate per animal, and the alkane technique is less precise than intake recorded using weigh bins. Repeatability of digestibility was moderate $(0.28$ and 0.37$)$ when digestibility was determined with acid-insoluble ash as an internal marker (Huhtanen et al., 2015) or a total faecal collection method (Cabezas-Garcia et al., 2017), respectively. These studies indicate that between-cow variation in digestibility alone is too small to explain the observed variation in feed efficiency.

Digestibility was positively associated with ECM production in Huhtanen et al.'s (2015) data set when the effects of DMI, LW and DIM were used as covariates in a mixed model analysis with random effects of experiment, diet within experiment and period within experiment, as follows:

$$
\begin{gathered}
\mathrm{ECM}(\mathrm{kg} / \text { day })=8.82+1.69 \times \mathrm{DMI}-0.0148 \times \mathrm{LW} \\
-0.0289 \times \mathrm{DIM}+0.0249 \times \mathrm{OMD}
\end{gathered}
$$

When these factors are held constant, a $10 \mathrm{~g} / \mathrm{kg}$ increase in OMD increases ECM production by $0.25 \mathrm{~kg} /$ day. The difference in digestibility corresponds to an increase in metabolisable energy (ME) intake of $\sim 3 \mathrm{MJ}$ (DMI $21 \mathrm{~kg} /$ day organic matter, 0.95 dry matter (DM); $1 \mathrm{~kg}$ digestible organic matter $=16 \mathrm{MJ}$ of ME). The marginal response to additional ME owing to improved digestion was $0.083 \mathrm{~kg} \mathrm{ECM} / \mathrm{MJ}$ of ME. This value is slightly lower than the typical marginal efficiency of ME utilisation for milk production $(0.10 \mathrm{~kg}$ ECM/MJ of ME). This slightly lower value could might be associated with a greater marginal $\mathrm{CH}_{4}$ production and increased digesta retention time in the rumen. The relationship between $\mathrm{CH}_{4}$ yield and digestibility suggests that some $25 \%$ to $30 \%$ of incremental digestible energy can be lost as $\mathrm{CH}_{4}$ in response to a slower passage rate.

Overall, the potential to improve feed efficiency by selecting cows for low $\mathrm{CH}_{4}$ emission or high digestibility at a constant feed intake level appears to be limited, especially given the positive relationship between $\mathrm{CH}_{4}$ yield and diet digestibility. Considering that differences in digesta passage rate affect both $\mathrm{CH}_{4}$ yield and digestibility, and that digestion rate is primarily a feed characteristic, rather than an animal trait, it seems unlikely that one can increase ME supply by 
selecting for improved digestibility while reducing $\mathrm{CH}_{4}$ emissions. The potential to improve digestibility is limited mainly to the cell wall fraction of feed because true digestibility of neutral detergent soluble materials is almost complete (Weisbjerg et al., 2004). Because the digesta passage rate is the main (perhaps only) animal factor contributing to cell wall digestibility, the potential for improving feed efficiency through genetic selection on digestibilty in high yielding dairy cows could be limited. Slowed passage will increase ruminal digesta pool size (rumen fill) and, consequently, limit intake potential.

Diet digestibility has been shown to be lower in low $\mathrm{CH}_{4}$ emitters than in high $\mathrm{CH}_{4}$ emitters in sheep (Pinares-Patiño et al., 2011), although one study found only a non-significant trend (Goopy et al., 2014). In a modelling study, Huhtanen et al. (2016) observed a negative relationship of digesta passage rate with $\mathrm{CH}_{4}$ yield and digestibility, with a positive relationship between $\mathrm{CH}_{4}$ yield and digestibility. The model simulations were based on observed variability in digesta passage rate determined by the rumen evacuation technique. The aforementioned model simulations and studies with sheep (Pinares-Patiño et al., 2003; Goopy et al., 2014) indicated that $\mathrm{CH}_{4}$ yield was positively associated with rumen digesta pool size. On average, a decrease of $1.0 \mathrm{~g} / \mathrm{kg}$ DM in $\mathrm{CH}_{4}$ yield was associated with a $10 \mathrm{~g} / \mathrm{kg}$ reduction in diet digestibility (Table 3). Assuming a gross energy concentration of $18.5 \mathrm{MJ} / \mathrm{kg} \mathrm{DM}$, a reduction of the $\mathrm{CH}_{4}$ yield by $1.0 \mathrm{~g} / \mathrm{kg}$ DM would be expected to be associated with a decrease ME intake by $0.185 \mathrm{MJ}$ (dietary gross energy concentration $18.5 \mathrm{MJ} / \mathrm{kg} \mathrm{DM}$ ), an effect three times greater than that associated with reducing $\mathrm{CH}_{4} \quad(0.055 \mathrm{MJ} ; 1 \mathrm{~g}$ $\mathrm{CH}_{4}=0.055 \mathrm{MJ}$ ).

Positive correlations ( 0.66 and 0.74 ) have been reported between $\mathrm{CH}_{4}$ yield and cellulose digestibility (Pinares-Patiño et al., 2003) and between $\mathrm{CH}_{4}$ yield and NDF digestibility (Pinares-Patiño and Clark, 2010). Strong positive relationships between $\mathrm{CH}_{4}$ yield expressed as a proportion of gross energy intake and energy digestibility could be derived from individual cow data published by Schiemann et al. (1970a and 1970b; Figure 4), indicating that the relationship between $\mathrm{CH}_{4}$ yield and digestibility is rather similar when differences in $\mathrm{CH}_{4}$ result from differences between cows at the same intake level or differences in feeding level, with differences in passage rate being the most likely causative factor. Hence, selection of low-emitting animals may reduce NDF digestibility, a more important characteristic of ruminants in human food production over monogastrics.

\section{Energy supply is affected by methane emission}

Johnson and Johnson's (1995) finding that energy losses in $\mathrm{CH}_{4}$ ranged from $2 \%$ to $12 \%$ of gross energy intake is often interpreted as indicating a great potential for improving efficiency of feed utilisation. However, this range represents extreme conditions, rather than variation among animals fed the same diet at the same level of intake. The lowest values were obtained from animals consuming a high concentrate ad libitum diet ( $>90 \%$ on a DM basis) and feedlot cattle, whereas the highest values were related to highly digestible diets fed at maintenance levels. For dairy cows eating $20 \mathrm{~kg}$ of DM/day (gross energy, $18.5 \mathrm{MJ} / \mathrm{kg} \mathrm{DM}$ ), each cow loses about $24 \mathrm{MJ}$ of energy as $\mathrm{CH}_{4}$ each day $(6.5 \%$ of gross energy intake) that otherwise could supply ME. Assuming that between-cow $\mathrm{CV}$ in $\mathrm{CH}_{4}$ yield is $10 \%$ at the same feeding level, $1 \mathrm{SD}$ unit reduction in $\mathrm{CH}_{4}$ represents $2.4 \mathrm{MJ}$ of ME. Using a value of 0.62 for the efficiency of ME utilisation for milk production, incremental ME supply from reduced $\mathrm{CH}_{4}$ would support $0.48 \mathrm{~kg} /$ day greater ECM yield, assuming that all incremental ME is partitioned towards the mammary glands and that diet digestibility is unchanged. Although this calculation assumes that there is no relationship between $\mathrm{CH}_{4}$ yield and digestibility, all experimental and modelling evidence indicates otherwise. It could be argued that it is possible to select animals that have low $\mathrm{CH}_{4}$ emissions and high digestibility. However, this is not very likely since digestibility is a function of digestion $\left(k_{d}\right)$ and passage $\left(k_{p}\right)$ rates: digestibility $=k_{d}\left(k_{d}+k_{p}\right)$. Both $\mathrm{CH}_{4}$ yield and digestibility are reduced when $k_{p}$ is increased, unless $k_{d}$ is increased enough to compensate for the change in $k_{p}$. However, $k_{d}$ is a feed-specific characteristic and therefore unlikely to be influenced by animal characteristics. The only feasible animal-related change that can positively influence digestibility would be increasing the buffering of rumen contents to

Table 3 Diet digestibility and methane $\left(\mathrm{CH}_{4}\right)$ yield ( $\mathrm{g} / \mathrm{kg}$ dry matter intake (DMI)) in high emitter (HE) and low emitter (LE) groups, and difference ( $\Delta$ ) in digestibility between HE and LE groups

\begin{tabular}{|c|c|c|c|c|c|c|}
\hline \multirow[b]{2}{*}{ Study } & \multirow[b]{2}{*}{ In vivo diet or model species } & \multicolumn{2}{|c|}{ Diet digestibility $(\mathrm{g} / \mathrm{kg})$} & \multicolumn{2}{|c|}{$\mathrm{CH}_{4}(\mathrm{~g} / \mathrm{kg} \mathrm{DMI})$} & \multirow[b]{2}{*}{$\Delta$ digestibility $\left(\mathrm{g} / \mathrm{kg}\right.$ per $\left.\Delta \mathrm{CH}_{4}\right)$} \\
\hline & & $\mathrm{HE}$ & LE & HE & LE & \\
\hline \multicolumn{7}{|l|}{ In vivo } \\
\hline Goopy et al. (2014) & & 664 & 648 & 23.5 & 20.8 & 5.9 \\
\hline Pinares-Patiño et al. (2011) & Pasture & 629 & 595 & 24.6 & 21.7 & 11.7 \\
\hline Pinares-Patiño et al. (2011) & Pellet & 634 & 581 & 10.8 & 6.4 & 12.0 \\
\hline \multicolumn{7}{|l|}{ Modelling } \\
\hline Huhtanen et al. (2016) & Cow & 758 & 715 & 24.4 & 20.4 & 10.8 \\
\hline Huhtanen et al. (2016) & Sheep & 773 & 731 & 29.2 & 25.0 & 10.0 \\
\hline Mean & & 692 & 654 & 22.5 & 18.9 & 10.1 \\
\hline
\end{tabular}




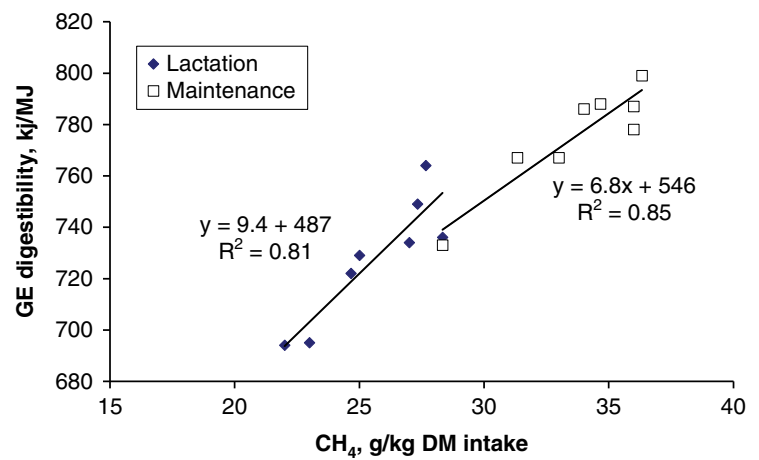

Figure 4 Relationship between methane $\left(\mathrm{CH}_{4}\right)$ yield and gross energy (GE) digestibility in dairy cows fed at maintenance and lactation production levels. Adapted from Schiemann et al. (1970a and 1970b). $\mathrm{DM}=$ dry matter.

maintain more optimal conditions for cell wall digestion. However, Cabezas-Garcia et al. (2017) found that there was no relationship between rumen $\mathrm{pH}$ and diet digestibility when the variations due to the diet and period effects were removed. Rumen $\mathrm{pH}$ was found to be a moderately repeatable trait $(t=0.46)$.

\section{Interactions between emissions and efficiency traits}

The current paradox over whether selection for either feed efficiency or limited $\mathrm{CH}_{4}$ emission produces a favourable correlated response in the other trait is related, at least partly, to trait definitions. Comparisons of divergent feed efficiency groups from numerous precision studies in which RFI data were recorded from a small number of animals have been inconsistent in identifying the relationships between $\mathrm{RFI}$ and $\mathrm{CH}_{4}$. For example, favourable relationships between $\mathrm{RFI}$ and $\mathrm{CH}_{4}$ production predicted from energy intake and the $\mathrm{CH}_{4} / \mathrm{CO}_{2}$ concentration ratio from cows maintained on concentrate feeders were reported for lactating Nordic red cattle (Negussie et al., 2014). Meanwhile, no relationships were detected in lactating Holstein, Simmental or Jersey cows fed forage-based diets (Münger and Kreuzer, 2008), nonlactating Holstein-Friesians fed alfalfa cubes or lactating Holstein-Friesians maintained on pasture grazing (Waghorn and Hegarty, 2011). One genetics study reported a favourable genetic correlation between $\mathrm{RFI}$ and $\mathrm{CH}_{4}$ production, but $\mathrm{CH}_{4}$ production was predicted from DMI, which may invalidate the result (de Haas et al., 2011).

It has been claimed that animals with a favourable feed efficiency eat less than their contemporaries for the same level of production and that because $\mathrm{CH}_{4}$ production is proportional to DMI, so that improving RFI should reduce $\mathrm{CH}_{4}$ production (Yan et al., 2010; Waghorn and Hegarty, 2011). However, empirical digestibility and digesta passage rate data from dairy cattle have shown that reduced $\mathrm{CH}_{4}$ yield is associated with reduced diet and cell wall digestion, such that those animals that are inefficient at digesting (extracting energy from) fibre produce less $\mathrm{CH}_{4}$ (Cabezas-Garcia et al., 2017).
This discordance in results, and thus interpretation of the relationship between feed efficiency and $\mathrm{CH}_{4}$ emissions, can be attributed, in part, to differing trait definitions, such as the definition of RFI. Often researchers and geneticists want to evaluate treatments and animals independent of scaling (i.e. large animal, high DMI, high milk and high $\mathrm{CH}_{4}$ ) and thus express efficiency as FCE or RFI. Similarly, $\mathrm{CH}_{4}$ emission can be expressed as a ratio $\left(\mathrm{CH}_{4}\right.$ yield or $\mathrm{CH}_{4}$ intensity), or as residual $\mathrm{CH}_{4}$ production, corrected for DMI or ECM. Both approaches have their advantages, but the largest difference between them is their assumption of the independence of their component traits. For example, in models (1) to (3), the definition of RFI omits phenotypic covariance between DMI and production trait 'sinks', bringing their phenotypic correlations close to zero, whereas genetic correlations can differ from zero. A more closely aligned method to actual breeding practices is to define DMI as genetically independent of breeding values for ECM, MBW and $\Delta \mathrm{LW}$, a concept we refer to as genetic RFI (RFIg). In this way, the genetic covariance between DMI and production traits is used to define RFIg as being genetically uncorrelated to production traits but still correlated to DMI. Notably, although RFIg is considered to be genetically uncorrelated to production traits, it remains phenotypically correlated to production traits. Both approaches require large numbers of records to estimate parameters among traits accurately.

Defining feed efficiency and $\mathrm{CH}_{4}$ emission traits as ratios is a useful metric for describing groups of animals, such as by treatment group, herd, breed or species. However, typically, ratio traits violate two statistical assumptions in a manner that can have consequences for defining the linear relationship (correlation or regression) between sets of traits, and thus make them less suitable for use in genetic selection (Zetouni et al., 2017). The first assumption violated is the assumption that a ratio is independent or uncorrelated to its numerator or denominator and the second is that the relationship between a ratio and its component traits is linear. Sutherland (1965) demonstrated the genetic interdependence between a ratio and its component traits, and further showed that the severity of nonlinearity between a ratio and its denominator trait is a function of the genetic correlation between the two component traits and the relative difference between their genetic and phenotypic variances. Consequently, there is a very narrow range where a ratio is independent of its denominator trait(s) and the relationship between the traits is linear. The inclusion of a biased correlation in a selection index results in suboptimal index weights and may lead to unpredictable genetic responses (Gunsett, 1984). The implications are that the correlation estimates, and thus the relationship between feed efficiency and $\mathrm{CH}_{4}$ emissions, when either or both are expressed as ratios, are likely to be a biased reflection of trait relationships. Therefore, it would be prudent to include the components of the ratios, each associated with its own appropriate weighting, in a selection index. 


\section{Impact and interaction with microbiome}

\section{Linking the rumen microbiome to feed efficiency and methane emission}

A critical challenge in rumen microbiology has been to link mircobiome composition, in terms of the functional roles of individual species, with cow phenotypes (Bickhart and Weimer, 2017). In the case of feed efficiency, small studies have been inconsistent in identifying operational taxonomic units (OTUs) in dairy cattle (Jami and Mizrahi, 2012; Jewell et al., 2015) and sheep (Shi et al., 2014). Grouping of OTUs or meta-transcriptomics at the species/genus level, or higher levels, has been variable across studies, often with opposing (positive $v$. negative) correlation values (Jami and Mizrahi, 2012; Shi et al., 2014). A notable example of this challenge can be seen with respect to OTUs belonging to the genus Prevotella, a predominant rumen bacterial genera with a large variety of metabolic functions but few cultured representatives (Stevenson and Weimer, 2007). In Holstein cattle divergent for RFI as well as Holstein and Swedish red cattle divergent for $\mathrm{CH}_{4}$ emission, a number of significant associations of Prevotella OTUs have been found across both sets of divergent groups (Jewell et al., 2015). Prevotella species need to be better characterised before it can be concluded that this genus underlies high and low divergent groups for $\mathrm{CH}_{4}$ production and RFI.

The known methanogenic capabilities of Archaea spurred research into Archaea associations with $\mathrm{CH}_{4}$ production (Wallace et al., 2014). It has been postulated that Archaea biomass yield should be proportional to $\mathrm{CH}_{4}$ production because Archaea rely almost solely on methanogenesis for ATP synthesis (Wallace et al., 2014). However, reviews of recent studies have suggested that production of hydrogen and other substrates of methanogenesis drive $\mathrm{CH}_{4}$ production (Tapio et al., 2017; Wallace et al., 2017). Thus, further research into other groups of rumen microbes, such as bacteria, protozoa and anaerobic fungi, is required to better characterise how the rumen microbiome relates to $\mathrm{CH}_{4}$ production.

\section{Potential diet-microbe interactions}

The rumen can be seen as a flow-through batch fermenter wherein the substrate and flow rate impact $\mathrm{CH}_{4}$ emissions and nutrient availability to the host through effects on the rumen microbiome. An extreme illustration of this notion can be seen in in vitro batch culture rumen fermentation studies, in which rumen fluid samples are pooled (to reduce host effects on microbes) and direct effects of additives on $\mathrm{CH}_{4}$ production and efficiency of VFA production are assessed (Yáñez-Ruiz et al., 2016). Such in vitro studies are often followed up with in vivo studies to validate the observed effects of screened compounds. This approach has resulted in numerous dietary strategies for $\mathrm{CH}_{4}$ mitigation based on substrate rumen microbiome interactions; this line of research is well reviewed and will not be discussed here (Hristov et al., 2013; Knapp et al., 2014; Patra, 2016). In general, these methods inhibit protozoa and, thus, associated abundant archaea serve as electron or hydrogen sinks, or are toxic to methanogens or inhibit methanogenesis directly (Patra, 2016). These strategies have aimed mostly to reduce $\mathrm{CH}_{4}$ emission, but in some instances have also aimed to improve feed efficiency (Hristov et al., 2013).

Interestingly, many of these strategies appear to be temporary and not cumulative, or to have negative influences on milk production (de Haas et al., 2014). Microbial adaption is the primary cause of effect waning (Wallace et al., 2002). However, these limitations can, in principle, be overcome by rotating and combining complementary additives (Klop et al., 2017).

There are exceptions, including nitrate and the patented compound 3-nitrooxypropanol, a methyl coenzyme M reductase inhibitor, which decreases $\mathrm{CH}_{4}$ emissions by up to $30 \%$ in lactating cows without compromising feed intake or milk production (Hristov et al., 2015). Its persistence is likely related to its narrow specificity, which reduces the risk of target microbes acquiring resistance. Thus, diet formulation, digestion rate and substrate passage rate have direct effects on rumen microbiome composition, feed efficiency and $\mathrm{CH}_{4}$ emissions. Rumen microbes may simply be indicators of digestibility and substrate availability. Notwithstanding, the rumen microbiome can adapt to some feed additives, demonstrating that substrate-microbe interactions are not unidirectional.

\section{Potential host-rumen interactions}

Increasing evidence suggests that microbes affect the development, health and metabolism of their hosts, and that the host itself affects its own rumen microbiome. Weimer et al. (2010) exchanged $\sim 95 \%$ of the rumen contents between cows and found that the rumen microbiome reverted almost completely back to pre-exchange characteristics, suggesting some level of host specificity of the rumen microbiome. Similar archaea:bacteria ratio differences were found among the progeny of eight animals from different breeds, suggesting that this ratio may be heritable (Roehe et al., 2016), in agreement with a large study of 750 Danish Holsteins in which $5 \% \sim 10 \%$ of rumen 16 s rRNA OTU counts were found to have significant heritability (Difford et al., 2016b). Such findings suggest that it may be possible to breed for the relative abundance of certain rumen microbes associated with favourable phenotypes. However, while ruminants' genomes are inherited, they are not born with a functional rumen microbiome but rather acquire it from their mothers and other animals in the environment (Jewell et al., 2015). Large cohort studies are needed to characterise genetic influences on host-microbe interactions, the results of which would also be useful for characterising and annotating rumen microbial species.

Holobionts - a holistic view of the host and its microbiome Complex digestive system phenotypes, such as $\mathrm{CH}_{4}$ emission or feed efficiency, are an expression of animal genetic, microbial community and environmental factors (Bickhart and Weimer, 2017). Holobiont theory holds that where the 
Improved feed efficiency and reduced emissions

holobiont is the collective of host and associated microbiomes, it is the holobiont that is subjected to joint selection for the best performance in an environment (Rosenberg and Zilber-Rosenberg, 2011; Bordenstein and Theis, 2015). Consequently, breeding or dietary management directed at traits like feed efficiency and $\mathrm{CH}_{4}$ emission without consideration of microbial factors are likely to be suboptimal. Alternatively, incorporating knowledge of the rumen microbiome in the selection for animals with higher than typical feed efficiency on particular diets may be key to future improvements in ruminant production.

\section{Conclusion}

The present comparative examination of methods used to express feed efficiency and greenhouse gas emission in dairy cattle indicates that feed efficiency assessment requires accurate measurement of feed intake as well as of related output traits, and that emissions should be measured in commercial herd environments. However, sufficient accuracy for estimation of breeding value may require examination of feed intake over short time periods. Emissions can be assessed accurately with relatively low-cost, high-capacity instruments. It is important that covariate traits in any model are accurately recorded, especially LW and BCS. Emission and efficiency data obtained during the relatively strongmobilisation, low-feed intake period of early lactation correlate weakly with data obtained during other phases of lactation, but should be included in recording protocols with records from other lactation stages. Because the relationship between feed efficiency and $\mathrm{CH}_{4}$ emission are likely to be a biased reflection of the relationship between the traits when either or both are expressed as ratios, the components of the ratios should be included, with appropriate weightings, in the selection index. The rumen microbiome plays a dual role in digestion, facilitating nutrient extraction from fibre-rich feed while also generating $\mathrm{CH}_{4}$. There are clear indications of interactions between bovine hosts and their microbiomes, and both show genetic variation and covariation. The strategy of preventing energy loss via eructed $\mathrm{CH}_{4}$ to make more energy available for lactation needs further study to clarify its feasibility and true potential, not least because the alternative is that energy can be lost as eructed hydrogen. The availability of low-cost, high-capacity recording methods can facilitate the development of genetic- and nutrition-based improvements in feed efficiency and reduction of emissions.

\section{Acknowledgements}

This study was supported financially by REMRUM (Innovation fund Denmark, Copenhagen, Denmark), 'Feed Utilization in Nordic Cattle' (Milk Levy Foundation, Skejby, Denmark) and 'REFFICO' (Green Development and Demonstration Program, GUDP, Denmark) grants. G.F. Difford was supported by a grant from the Erasmus-Mundus EGS-ABG program and graduate school.

\section{Declaration of interest}

The authors declare no conflict of interest.

\section{Ethics statement}

All handling of animals was conducted according to a protocol approved by The Animal Experiments Inspectorate, Danish Veterinary and Food Administration, Ministry of Environment and Food of Denmark (Approval number 2016-15-0201-00959).

\section{Software and data repository resources}

None of the data were deposited in an official repository.

\section{References}

Arndt S, Cohen G, Alliger RJ, Swayze VW and Andreasen NC 1991. Problems with ratio and proportion measures of imaged cerebral structures. Psychiatry Research: Neuroimaging 40, 79-89.

Barnhart HX, Haber MJ and Lin LI 2007. An overview on assessing agreement with continuous measurements. Journal of Biopharmaceutical Statistics 17, 529-569.

Bell MJ, Potterton SL, Craigon J, Saunders N, Wilcox RH, Hunter M, Goodman JR and Garnsworthy PC 2014. Variation in enteric methane emissions among cows on commercial dairy farms. Animal 8, 1540-1546.

Berry DP, Coffey MP, Pryce JE, de Haas Y, Løvendahl P, Krattenmacher N, Crowley JJ, Wang Z, Spurlock D, Weigel K, Macdonald K and Veerkamp RF 2014. International genetic evaluations for feed intake in dairy cattle through the collation of data from multiple sources. Journal of Dairy Science 97, 3894-3905. Berry DP and Crowley JJ 2013. Cell Biology Symposium : genetics of feed efficiency in dairy and beef cattle. Journal of Animal Science 91, 1594-1613.

Berry DP, Horan B, O'Donovan M, Buckley F, Kennedy E, McEvoy M and Dillon P 2007. Genetics of grass dry matter intake, energy balance and digestibility in Irish dairy cows. Journal of Dairy Science 90, 4835-4845.

Bickhart DM and Weimer PJ 2017. Host-rumen microbe interactions may be leveraged to improve the productivity of dairy cows. Journal of Dairy Science 101, 1-10.

Bordenstein SR and Theis KR 2015. Host biology in light of the microbiome: ten principles of holobionts and hologenomes. PLoS Biology 13,1-23.

Cabezas-Garcia EH, Krizsan SJ, Shingfield KJ and Huhtanen P 2017. Betweencow variation in digestion and rumen fermentation variables associated with methane production. Journal of Dairy Science 100, 4409-4424.

Capper JL, Cady RA and Bauman DE 2009. The environmental impact of dairy production: 1944 compared with 2007. Journal of Animal Science 87, 2160-2167.

Connor EE 2015. Invited review: improving feed efficiency in dairy production: challenges and possibilities. Animal 9, 395-408.

Czerkawski JW 1986. An introduction to rumen studies. Pergamon Press, Elmsford, NY, USA.

de Haas Y, Pryce JE, Berry DP and Veerkamp RF 2014. Genetic and genomic solutions to improve feed efficiency and reduce environmental impact of dairy cattle. Paper presented at the 10th World Congress Applied to Livestock Production, 17-22 August 2014, Vancouver, Canada.

de Haas Y, Windig JJ, Calus MPL, Dijkstra J, de Haan M, Bannink A and Veerkamp RF 2011. Genetic parameters for predicted methane production and potential for reducing enteric emissions through genomic selection. Journal of Dairy Science 94, 6122-6134.

Dehareng F, Delfosse C, Froidmont E, Soyeurt H, Martin C, Gengler N, Vanlierde $A$ and Dardenne P 2012. Potential use of milk mid-infrared spectra to predict individual methane emission of dairy cows. Animal 6, 1694-1701.

Denman SE and McSweeney CS 2014. The early impact of genomics and metagenomics on ruminal microbiology. Annual Review in Animal Biosciences 3, 1-19.

Difford GF, Lassen J and Løvendahl P 2016a. Interchangeability between methane measurements in dairy cows assessed by comparing precision and 
agreement of two non-invasive infrared methods. Computers and Electronics in Agriculture 124, 220-226.

Difford GF, Lassen J and Løvendahl P 2016b. Genes and microbes, the next step in dairy cattle breeding. Paper presented at the 67th Annual Meeting of the European Association for Animal Production, 29 August-2 September 2016, Belfast, UK.

Firkins JL and Yu Z 2006. Characterisation and quantification of the microbial populations in the rumen. In Ruminant physiology, digestion, metabolism and impact of nutrition on gene expression, immunology and stress (ed. Sejrsen, K, Hvelplund, T and Nielsen, M0), pp. 19-54. Wageningen Academic Publishers, Wageningen, the Netherlands.

Gerber PJ, Steinfeld H, Henderson B, Mottet A, Opio C, Dijkman J, Falucci A and Tempio $G$ 2013. Tackling climate change trough livestock - a global assessment of emissions and mitigation opportunities. Food and Agriculture Organization of the United Nations (FAO), Rome, Italy.

Goopy JP, Donaldson A, Hegarty R, Vercoe PE, Haynes F, Barnett M and Oddy VH 2014. Low-methane yield sheep have smaller rumens and shorter rumen retention time. British Journal of Nutrition 111, 578-585.

Gunsett FC 1984. Linear selection to improve traits defined as ratios. Journal of Animal Science 59, 1185-1193.

Hammond KJ, Crompton LA, Bannink A, Dijkstra J, Yáñez-Ruiz DR, O’Kiely P, Kebreab $E$, Eugenè MA, $Y u$ Z, Shingfield KJ, Schwarm A, Hristov AN and Reynolds CK 2016a. Review of current in vivo measurement techniques for quantifying enteric methane emission from ruminants. Animal Feed Science and Technology 219, 13-30.

Hammond KJ, Jones AK, Humphries DJ, Crompton LA and Reynolds CK 2016b. Effects of diet forage source and neutral detergent fiber content on milk production of dairy cattle and methane emissions determined using GreenFeed and respiration chamber techniques. Journal of Dairy Science 99, 7904-7917.

Hardie LC, VandeHaar MJ, Tempelman RJ, Weigel KA, Armentano LE, Wiggans GR, Veerkamp RF, de Haas Y, Coffey MP, Connor EE, Hanigan MD, Staples C, Wang Z, Dekkers JCM and Spurlock DM 2017. The genetic and biological basis of feed efficiency in mid-lactation Holstein dairy cows. Journal of Dairy Science 100, 9061-9075.

Herd RM and Arthur PF 2014. Physiological basis for residual feed intake. Journal of Animal Science 87 (suppl. E), E64-E71.

Herd RM, Oddy VH and Richardson EC 2004. Biological basis for variation in residual feed intake in beef cattle. 1 . Review of potential mechanisms. Australian Journal of Experimental Agriculture 44, 423-430.

Hooven NW, Miller RH and Smith JW 1972. Relationships among whole- and part-lactation gross feed efficiency, feed consumption, and milk yield. Journal of Dairy Science 55, 1113-1122.

Hristov AN, Kebreab E, Niu M, Oh J, Bannink A, Bayat AR, Boland TB, Brito AF, Casper DP, Crompton LA, Dijkstra J, Eugène M, Garnsworthy PC, Haque N, Hellwing ALF, Huhtanen P, Kreuzer M, Kuhla B, Lund P, Madsen J, Martin C, Moate PJ, Muetzel S, Muñoz C, Peiren N, Powell JM, Reynolds CK, Schwarm A, Shingfield KJ, Storlien TM, Weisbjerg MR, Yáñez-Ruiz DR and Yu Z 2018. Symposium review: uncertainties in enteric methane inventories, measurement techniques, and prediction models. Journal of Dairy Science 101, 6655-6674.

Hristov AN, Oh J, Firkins JL, Dijkstra J, Kebreab E, Waghorn G, Makkar HPS, Adesogan AT, Yang W, Lee C, Gerber PJ, Henderson B and Tricarico JM 2013. Special topics - mitigation of methane and nitrous oxide emissions from animal operations: I. A review of enteric methane mitigation options. Journal of Animal Science 91, 5045-5069.

Hristov A, Oh J, Giallongo F, Frederick T, Harper M, Weeks H, Branco A, Moate P, Deighton M, Williams SR, Kindermann M and Duval S 2015. An inhibitor persistently decreased enteric methane emission from dairy cows with no negative effect on milk production. Proceedings of the National Academy of Sciences USA 112, 10663-10668.

Huhtanen P, Cabezas-Garcia EH, Utsumi S and Zimmerman S 2015. Comparison of methods to determine methane emissions from dairy cows in farm conditions. Journal of Dairy Science 98, 3394-3409.

Huhtanen P, Ramin M and Cabezas-Garcia EH 2016. Effects of ruminal digesta retention time on methane emissions: a modelling approach. Animal Production Science 56, 501-506.

Hurley AM, López-Villalobos N, McParland S, Kennedy E, Lewis E, O'Donovan M, Burke JL and Berry DP 2016. Interrelationships among alternative definitions of feed efficiency in grazing lactating dairy cows. Journal of Dairy Science 99, 468479 .
Jami E and Mizrahi I 2012. Composition and similarity of bovine rumen microbiota across individual animals. PLoS One 7, 1-8.

Jewell KA, McCormick CA, Odt CL, Weimer PJ and Suen G 2015. Ruminal bacterial community composition in dairy cows is dynamic over the course of two lactations and correlates with feed efficiency. Applied Environmental Microbiology 81, 4697-4710.

Johnson KA and Johnson DE 1995. Methane emissions from cattle. Journal of Animal Science 73, 2483-2492.

Kittelmann S, Pinares-Patiño CS, Seedorf H, Kirk MR, Ganesh S, McEwan JC and Janssen PH 2014. Two different bacterial community types are linked with the low-methane emission trait in sheep. PLoS One 9, e103171.

Klop G, Dijkstra J, Dieho K, Hendriks WH and Bannink A 2017. Enteric methane production in lactating dairy cows with continuous feeding of essential oils or rotational feeding of essential oils and lauric acid. Journal of Dairy Science 100, 3563-3575.

Knapp JR, Laur GL, Vadas PA, Weiss WP and Tricarico JM 2014. Invited review: enteric methane in dairy cattle production: quantifying the opportunities and impact of reducing emissions. Journal of Dairy Science 97, 3231-3261.

Lassen J and Løvendahl P 2016. Heritability estimates for enteric methane production in dairy cattle using non-invasive methods. Journal of Dairy Science 99, 1959-1967.

Lassen J, Løvendahl P and Madsen J 2012. Accuracy of non-invasive breath measurements using Fourier transform infrared methods on individual cows. Journal of Dairy Science 95, 890-898.

Li B, Berglund B, Fikse WF, Lassen J, Lidauer MH, Mäntysaari P and Løvendahl P 2017. Neglect of lactation stage leads to naive assessment of residual feed intake in dairy cattle. Journal of Dairy Science 100, 9076-9084.

Liinamo A-E, Mantysaari P, Lidauer MH and Mantysaari EA 2015. Genetic parameters for residual energy intake and energy conversion efficiency in Nordic Red dairy cattle. Acta Agricultura Scandinavica, Section A, Animal Science 65, 63-72.

Madsen J, Bjerg BS, Hvelplund T, Weisbjerg MR and Lund P 2010. Methane and carbon dioxide ratio in excreted air for quantification of methane production in ruminants. Livestock Science 129, 223-227.

McAllister TA and Newbold CJ 2008. Redirecting rumen fermentation to reduce methanogenesis. Australian Journal of Experimental Agriculture 48, 7-13.

Mehtiö T, Rinne $M$, Nyholm L, Mäntysaari $P$, Sairanen A, Mäntysaari EA, Pitkänen T and Lidauer MH 2016. Cow-specific diet digestibility predictions based on near-infrared reflectance spectroscopy scans of faecal samples. Journal of Animal Breeding and Genetics 133, 115-125.

Moss AR, Jouany JP and Newbold J 2000. Methane production by ruminants : its contribution to global warming. Annales de Zootechnie 49, 231-253.

Münger A and Kreuzer M 2008. Absence of persistent methane emission differences in three breeds of dairy cows. Australian Journal of Experimental Agriculture 48, 77-82.

Negussie E, de Haas Y, Dehareng F, Dewhurst RJ, Dijkstra J, Gengler N, Morgavi DP, Soyeurt H, van Gastelen S, Yan T and Biscarini F 2017. Invited review: largescale indirect measurements for enteric methane emissions in dairy cattle: a review of proxies and their potential for use in management and breeding decisions. Journal of Dairy Science 100, 2433-2453.

Negussie E, Mäntysaari P, Mäntysaari EA and Lidauer M 2014. Animal wise variation in enteric output traits and its relationship with feed efficiency in dairy cattle: a longitudinal model analysis. Paper presented at the 10th World Congress Applied to Livestock Production, 17-22 August 2014, Vancouver, Canada. Patra AK 2016. Recent advances in measurement and dietary mitigation of enteric methane emissions in ruminants. Frontiers in Veterinary Science 3, 1-17. Pinares-Patiño CS and Clark H 2010. Rumen function and digestive parameters associated with methane emissions in dairy cows. Paper presented at the 4th Australasian Dairy Science Conference, 31 August-2 September 2010, Christchurch, New Zealand.

Pinares-Patiño CS, Ebrahimi SH, McEwan JC, Clark H and Luo D 2011. Is rumen retention time implicated in sheep differences in methane emission? Proceedings of New Zealand Society of Animal Production 71, 219-222.

Pinares-Patiño CS, Ulyatt MJ, Lassey KR, Barry TN and Holmes CW 2003. Rumen function and digestion parameters associated with differences between sheep in methane emissions when fed chaffed Lucerne hay. Journal of Agricultural Science 140, 205-214. 
Ramin M and Huhtanen P 2013. Development of equations for predicting methane emissions from ruminants. Journal of Dairy Science 96, 24762493.

Raubenheimer D 1995. Problems with ratio analysis in nutritional studies. Functional Ecology 9, 21-29.

Roehe R, Dewhurst R, Duthie C-A, Rooke JA, McKain N, Ross DW, Hyslop JJ, Waterhouse A, Freeman TC, Watson M and Wallace JR 2016. Bovine host genetic variation influences rumen microbial methane production with best selection criterion for low methane emitting and efficiently feed converting hosts based on metagenomic gene abundance. PLoS Genetics 12, 1-28.

Rosenberg E and Zilber-Rosenberg I 2011. Symbiosis and development: the hologenome concept. Birth Defects Research, Part C - Embryo Today Review 93 56-66.

Roy A 2009. An application of linear mixed effects model to assess the agreement between two methods with replicated observations. Journal of Biopharmaceutical Statistics 19, 150-173.

Russell JB, O'Connor JD, Fox DG, Van Soest PJ and Sniffen CJ 1992. A net carbohydrate and protein system for evaluating cattle diets: I. Ruminal fermentation. Journal of Animal Science 70, 3551-3561.

Schiemann R, Jentsch W, Hoffmann L and Wittenburg H 1970a. Die Verwertung der Futterenergie für die Milchproduktion. Archiv für Tierernährung 20, 227251.

Schiemann R, Jentsch W and Wittenburg H 1970b. Zur Abhängigkeit der Verdaulichkeit der Energie und der Nährstoffe von der Höhe der Futteraufnahme und der Rationszusammensetzung bei Milchkühen. Archiv für Tierernährung 21, 223-240.

Shetty N, Difford G, Lassen J, Løvendahl P and Buitenhuis AJ 2017. Predicting methane emissions of lactating Danish Holstein cows using Fourier transform mid-infrared spectroscopy of milk. Journal of Dairy Science 100, 9052-9060.

Shetty N, Løvendahl P, Lund MS and Buitenhuis AJ 2016. Prediction and validation of residual feed intake and dry matter intake in Danish lactating dairy cows using mid-infrared spectroscopy of milk. Journal of Dairy Science 100 , 253-264.

Shi W, Moon CD, Leahy SC, Kang D, Froula J, Kittelmann S, Fan C, Deutsch S, Gagic D, Seedorf H, Kelly WJ, Atua R, Sang C, Soni P, Li D, Pinares-Patiño CS, McEwan JC, Janssen PH, Chen F, Visel A, Wang Z, Attwood GT and Rubin EM 2014. Methane yield phenotypes linked to differential gene expression in the sheep rumen microbiome. Genome Research 24, 1517-1525.

Smuts M, Meissner HH and Cronjé PB 1995. Retention time of digesta in the rumen: its repeatability and relationship with wool production of Merino rams. Journal of Animal Science 73, 206-210.

Stevenson DM and Weimer PJ 2007. Dominance of Prevotella and low abundance of classical ruminal bacterial species in the bovine rumen revealed by relative quantification real-time PCR. Applied Microbiology and Biotechnology 75, 165-174.

Sutherland TM 1965. The correlation between feed efficiency and rate of gain, a ratio and its denominator. Biometrics 21, 739-749.

Tapio I, Snelling TJ, Strozzi F and Wallace RJ 2017. The ruminal microbiome associated with methane emissions from ruminant livestock. Journal of Animal Science and Biotechnology 8, 2-11.
Tempelman RJ, Spurlock DM, Coffey M, Veerkamp RF, Armentano LE, Weigel KA, de Haas Y, Staples CR, Connor EE, Lu Y and VandeHaar MJ 2015. Heterogeneity in genetic and nongenetic variation and energy sink relationships for residual feed intake across research stations and countries. Journal of Dairy Science 98, 2013-2026.

VandeHaar MJ, Armentano LE, Weigel K, Spurlock DM, Tempelman RJ and Veerkamp RF 2016. Harnessing the genetics of the modern dairy cow to continue improvements in feed efficiency. Journal of Dairy Science 99, 4941-4954.

Vanlierde A, Vanrobays M-L, Dehareng F, Froidmont E, Soyeurt H, McParland S, Lewis E, Deighton MH, Grandl F, Kreuzer M, Gredler B, Dardenne P and Gengler N 2015. Hot topic: innovative lactation-stage-dependent prediction of methane emissions from milk mid-infrared spectra. Journal of Dairy Science 98, 5740-5747. Van Soest PJ 1994. Nutritional ecology of the ruminant. Cornell University Press, Ithaca, NY. pp. 476.

Waghorn GC and Hegarty RS 2011. Lowering ruminant methane emissions through improved feed conversion efficiency. Animal Feed Science and Technology 166-167, 291-301.

Wallace RJ, McEwan NR, McIntosh FM, Teferedegne B and Newbold CJ 2002. Natural products as manipulators of rumen fermentation. Asian-Australasian Journal of Animal Science 15, 1458-1468.

Wallace RJ, Rooke JA, Duthie CA, Hyslop JJ, Ross DW, McKain N, De Souza SM, Snelling TJ, Waterhouse A and Roehe R 2014. Archaeal abundance in postmortem ruminal digesta may help predict methane emissions from beef cattle. Scientific Reports 4, 1-8.

Wallace RJ, Snelling TJ, McCartney CA, Tapio I and Strozzi F 2017. Application of meta-omics techniques to understand greenhouse gas emissions originating from ruminal metabolism. Genetics Selection Evolution 49, 9.

Weimer PJ, Mantovani HC and Man SLC 2010. Host specificity of the ruminal bacterial community in the dairy cow following near-total exchange of ruminal contents. Journal of Dairy Science 93, 5902-5912.

Weisbjerg MR, Hvelplund T and Søegaard K 2004. Prediction of digestibility of nutrient detergent solubles using the Lucas principle. Journal of Animal and Feed Science 13 (suppl. 1), 239-242.

Wolin MJ 1960. A theoretical rumen fermentation balance. Journal of Dairy Science 43, 1452-1459.

Yan T, Agnew RE, Gordon FJ and Porter MG 2000. Prediction of methane energy output in dairy and beef cattle offered grass silage-based diets. Livestock Production Science 64, 253-263.

Yan T, Mayne CS, Gordon FG, Porter MG, Agnew RE, Patterson DC, Ferris CP and Kilpatrick DJ 2010. Mitigation of enteric methane emissions through improving efficiency of energy utilization and productivity in lactating dairy cows. Journal of Dairy Science 93, 2630-2638.

Yáñez-Ruiz DR, Bannink A, Dijkstra J, Kebreab E, Morgavi DP, O'Kiely P, Reynolds CK, Schwarm A, Shingfield KJ, Yu Z and Hristov AN 2016. Design, implementation and interpretation of in vitro batch culture experiments to assess enteric methane mitigation in ruminants-a review. Animal Feed Science and Technology 216, 1-18.

Zetouni L, Henryon M, Kargo M and Lassen J 2017. Direct multitrait selection realizes the highest genetic response for ratio traits. Journal of Animal Science $95,1921-1925$ 